\title{
Editorial
}

\author{
Michael Stark
}

\section{Introduction to the cesarean section articles}

https://doi.org/10.1515/jpm-2021-0381

Cesarean section is the most frequently done operation on women. Therefore, it was decided to dedicate this special issue to different aspects of this operation, where obstetricians and researchers from different countries share their experience and knowledge.

In the 1930s, the rate of cesarean section in Europe was about $2-3 \%$, [1]. These days the cesarean numbers are rising constantly all over the world. The rate of cesarean section in the Dominican Republic reached 58.1\% and is the highest in the world. In Brazil the rate is 55.8\% [2], in Egypt 54\% [3], and the range among the different American states is $22-38.5 \%$ [4].

In $47.2 \%$ of the countries, the cesarean rate is over $15 \%$; in Latin America, the Caribbean, Europe, North America, and Oceania we find the highest values [5].

There are various reasons for these extremely high numbers, and certainly for the variations between countries and among hospitals in the same country, and sometimes even in the same cities. These are, among others, the fear of the obstetricians of possible lawsuits, and the requests for cesareans on demand. One of the outcomes of the high rate of cesareans are abnormal placentation during the next pregnancies, and as a result excessive bleeding, coagulation problems where even hysterectomies might result. Therefore, it is of utmost importance to reduce as much as possible unnecessary operations without risking the mothers and newborns.

Very often women who had an emergency cesarean section, or were operated for different reasons such as abnormal presentation, toxemia or bleeding, are expecting again, where it seems that normal birth is not an option. It is suggested not to plan the operation before fetal maturation. This will prevent respiratory problems in the newborn. The outcome of cesarean sections done earlier can be associated with non-favorable outcomes, early ones, such as the need for oxygen support due to respiratory distress syndrome, including the need to use

Corresponding author: Prof. Dr. Michael Stark, President, The New European Surgical Academy (NESA), Unter den Linden 21, 10117 Berlin, Germany, Phone: +49 (0)30 2391 0916, Fax: +49 (0)30 2092 4200, Mobile: +49 (0)174 992 3614, E-mail: mstark@nesacademy.org the intensive care unit and late outcomes such as retinopathy of prematurity [6] or cerebral palsy [7].

And indeed, Jis Thomas et al. from Doha, Qatar, who evaluated the outcome of newborns delivered by cesareans before the 39th week, showed that respiratory distress syndrome, the need for respiration, and the use of intensive care units were significantly higher in these newborns as compared to those who were delivered after the 39th week [8]. The authors followed the Society for Maternal-Fetal Medicine which does not advocate the routine administration of steroids before early-term cesareans. This issue lately became controversial [9]. There are various arguments for not using steroids, such as possible hypoglycemia in the newborn, which might affect the child's development [10].

As the administration of steroids to women before a premature delivery is still the routine in many medical centers, this question should be further explored.

In Germany, nearly 50\% of trials of labor are done after previous cesareans. Dr. Anastasia Lazarou and colleagues from the Charite University Hospital in Berlin, Germany, discussed this practice in a well-designed study, done in order to predict the chance of a successful vaginal birth after a previous cesarean [11]. The study was done by using, next to Grobman's parameters, a binary-logistic regression analysis as well as additional variables. Among 348 women who met the inclusion criteria for a trial of labor, $51.7 \%$ had a successful birth, 18.4\% had a vacuum delivery, and only 29.9\% were operated.

Certainly, the prerequisites for the trial of labor need to be followed carefully, such as examining the previous post-operative history, the ultrasound evaluation of the uterine scar, the estimated birth weight, and the availability of an operation room.

Additional ways should be evaluated in order to predict possible risks and successes of post-cesarean deliveries, and to compare them to the models of Grobman and Fagerberg. Lately, the machine learning model was introduced, which seems to predict with high sensitivity the chance of successful delivery [12].

Many factors should be taken into account when trying to predict the chance of normal birth, such as the influence of obesity on labor induction: a systematic review and meta-analysis showed that the rate of cesarean deliveries 
following induction of labor is more common among obese women compared with those of normal weight [13].

Motivation and participation of the women is needed when vaginal birth after cesarean section is considered. Dorothea M. Koppes et al. from the Netherlands in a multicenter study presents an original approach by offering the use of a Decision Aid Questionnaire in order to assist women in their decision to try a vaginal birth [14]. The decision aid includes information about the women's previous experience, provides information about risks and benefits of a trial of labor, as well as the knowledge of all existing options, and the women's individual birthing plan. The decision aid is available in four languages; and therefore, it is accessible to different populations in the country. The study included 30 hospitals. When the decision aid was used, a statistically significant difference among hospitals was shown concerning the probability of a successful vaginal birth, and its use improved the probability of a successful vaginal birth. It is not improbable that if the Decision Aid Questionnaire will be used in countries where the rate of vaginal delivery following cesarean is low, it will encourage more women to avoid a repeated operation.

In a study where women with class III obesity underwent induction of labor, the cesarean rate was about $50 \%$. Nulliparity, height, and low cervical score were significant factors for performing the operation [15].

Therefore, the study of Eberle et al. from McGill University in Montreal. Canada, is of interest, as it is a large cohort sized report which retrospectively evaluated 2,147,014 singleton vertex deliveries between 39 and 43 pregnancy weeks in women with a BMI of 30 or more, and with no previous cesarean [16]. Among these 375,928 women were induced at the 39 th week and $1,771,086$ were not.

The Cesarean section rate in the induced group was $20.5 \%$ compared to $24.68 \%$ in the non-induced.

There are different methods to induce labor, but the evidence on methods of induction of labor after previous Cesarean section is inadequate [17]. However, with no doubt, induced labor could prevent a repeated operation and should always be considered in obese women.

There are different ways to induce labor in postcesarean section women. Josefine Koenigbauer et al. from different German centers compared a mechanical labor stimulation method by using the osmotic dilator (Dilapan) to the use of prostaglandins (Dinoprostone, Minprostin) [18]. The time to the onset of labor was longer in the Dilapan group, and parturients in this group required significantly more frequent additional oxytocin labor augmentation (76\% as compared to $43.1 \%$ ).
Several studies already compared the different ways of induction after previous cesarean section [19]. The use of labor stimulation by mechanical means such as the Atad catheter is already well established [20].

However, this study shows that the osmotic dilator is as effective and safe as the usage of prostaglandins and should considered as a valid option for labor induction in women who had a previous cesarean.

Cesarean sections are done in different ways even at the same departments, and therefore it is difficult to compare the outcomes as long as the surgical technique in use is not standardized. The Misgav Ladach (Stark Cesarean) method which is presented here is an evidence-based operation [21]. This method has been subjected to scores of studies comparing it to the traditional time-honored methods. With no exception its superiority has been shown in regard to the operation time, blood loss, need for analgesics, febrile morbidity, and costs. In this operation, the modified Joel-Cohen abdominal incision is used, in which just two instruments are needed, a scalpel and scissors. The uterine incision is done below the bladder plica and the uterus is sutured with only one continuous layer. Both peritoneal layers are left open and the abdomen is closed just with a continuous suturing of the fascia and a few Donati skin sutures. This method is suggested as a standardized method for universal use.

However, the suggested single layer closure of the uterus is questioned in an online survey presented by Celine Kaps et al. from the Charite University Hospital in Berlin, Germany [22]. Obstetrical departments in 160 hospitals responded to a questionnaire about their method of suturing the uterus in cesarean section. The survey reveals that the methods in use were single layer continuous sutures (in hospitals with a high birth rate, maternal care level IV and III). Single layer locked technique (in hospitals with low birth rates), double-layer continuous sutures (used in five hospitals with high median birth rates), and interrupted sutures (which was only done in six hospitals).

Except in the presented Misgav Ladach cesarean method, there are no definite recommendations by the different associations for a unified way of the uterine closure, and the most commonly used ways are continuous or locked single layer, as well as the interrupted sutures. The outcomes of the different studies seem to be controversial, because some claim that the result of double-layer closure is a thicker uterine wall whereas others cannot find any differences concerning the thickness of the uterine wall in ultrasound controls.

The confusing factor is the lack of standardization in the different presented studies. Meta-analyses cannot be 
reliable if no standardized and unified methods are used in the examined groups [23]. Some obstetricians open the uterus above the bladder plica where the thickness of the uterine wall is larger than in the lower segment, claiming short operating time and incision-delivery interval, reduced blood loss, and need for analgesics [24] while others believe that the uterine incision should be done as low as possible [25], with the justification of a lower percentage of muscle fibers in the lower segment [26].

Standardization applies also to the suture material in use, and even to the size of the needle in use, because the bigger the needle, the less suture material is left behind. This might have a role in the healing process, because the less suture material left behind, the less foreign body reaction. Involution of the uterus starts immediately after the operation, and the sutures will anyhow loosen in time, so probably there are no benefits to suturing more than needed for immediate hemostasis, and the less suture material left behind, which is the case when one layer with a big needle is done, less reaction to the suture material left behind occurs, which might weaken the scar [27]

Christina Pulvermacher et al. from the universities of Bonn and Cologne in Germany analyzed the rate of the cesarean sections using the Robson's 10 group classification in hospitals with different levels of care [28]. As expected, variations among the different hospitals were shown, probably due to different populations and the different clinical routines. The use of the Robson classification could contribute to the reduction of the cesarean section rate in case each indication is discussed before a final decision. This classification was proposed by the WHO as a global standard for assessing, monitoring, and comparing the rate of cesarean sections among different hospitals [29]. The Robson classification enables objective comparison of the indications for cesarean sections in different institutions, as was shown in this study.

It is highly suggested that the Robson classification should be used for internal audits in each hospital. It enables defining and controlling the accuracy of the surgical indications, certainly in a planned first cesarean section. It is important to perform a cesarean section only for justified indication, and each non-emergency case should be discussed and controlled, for example, by a required documented second opinion.

Michel Odent's article: "Three kinds of cesarean sections: the fetal/neonatal perspective" concludes this issue [30]. Michel Odent is well known all over the world for his original, philosophical and constructive ideas and methods, such as the introduction of the water deliveries and his original insight into the modification of the parturient psychological mode. He presents here three kinds of cesarean sections, the pre-labor, the in-labor emergency cesarean, and the in-labor non-emergency cesarean which is not included in the Robson classification. This article gives insight into the influence of each one of these cesareans on the newborn's maturity, and the ability to adjust to his new environment.

No doubt the introduction of the cesarean sections in the 19th century saved the lives of many women and babies. However, it seems that the rising numbers during recent years are not justified and are causing complications and problems. There are certainly good reasons to perform this operation in case the parturient or the newborn is at risk. Many unjustified cesareans are the reason for several unnecessary risks, and therefore it is our duty to limit this operation only for justified reasons. This can be done when each operation, except the obvious emergency ones, should be discussed, preferably during the daily staff meeting, and the decision should be explained and documented.

Research funding: None declared.

Author contributions: Single author article. Competing interests: Author states no conflict of interest.

\section{References}

1. Stark L. Auswertung von 1000 Anstaltsgeburten. Monatsschr Geburtshilfe Gynäkol 1931;89:161.

2. Rudey EL, Leal MDC, Rego G. Cesarean section rates in Brazil: trend analysis using the Robson classification system. Medicine (Baltim) 2020;99:e19880.

3. Jadoon B, Assar TM, Nucier AAAR, Raziq HEA, Abd El-Azym Saad AS, Megahed Amer W. Analysis of the cesarean section rate using the 10-Group Robson classification at Benha University Hospital, Egypt. Women Birth 2020;33:e105-10.

4. Cesarean delivery rate by state. Available from: https://www.cdc. gov/nchs/pressroom/sosmap/cesarean_births/cesareans.htm [Accessed 2019].

5. Zizza A, Tinelli A, Malvasi A, Barbone E, Stark M, De Donno A, et al. Caesarean section in the world: a new ecological approach. J Prev Med Hyg 2011;52:161-73.

6. Hoppe G, Yoon S, Gopalan B, Savage AR, Brown R, Case K, et al. Comparative systems pharmacology of HIF stabilization in the prevention of retinopathy of prematurity. Proc Natl Acad Sci U S A 2016;113:E2516-25.

7. MacLennan AH, Thompson SC, Gecz J. Cerebral palsy: causes, pathways, and the role of genetic variants. Am J Obstet Gynecol 2015;213:779-88.

8. Jis Thomas J, Olukade TO, Naz A, Salama H, Al-Qubaisi M, Al Rifai H, et al. The neonatal respiratory morbidity associated with early term caesarean section-an emerging pandemic. J Perinat Med 2021;49:767-72. 
9. Shanks AL, Grasch JL, Quinney SK, Haas DM. Controversies in antenatal corticosteroids. Semin Fetal Neonatal Med 2019;24: 182-8.

10. Groom KM. Antenatal corticosteroids after 34 weeks gestation: do we have the evidence? Semin Fetal Neonatal Med 2019;24:189-96.

11. Lazarou A, Oestergaard M, Netzl J, Siedentopf J-P, Henrich W. Vaginal birth after cesarean (VBAC): fear it or dare it? Perinat Med 2021;49:773-82.

12. Lindblad Wollmann C, Hart KD, Liu C, Caughey AB, Stephansson 0 , Snowden JM. Predicting vaginal birth after previous cesarean: using machine-learning models and a populationbased cohort in Sweden. Acta Obstet Gynecol Scand 2021;100: 513-20.

13. Ellis JA, Brown CM, Barger B, Carlson NS. Influence of maternal obesity on labor induction: a systematic review and metaanalysis. J Midwifery Wom Health 2019;64:55-67.

14. Koppes DM, van Hees MS, Koenders VM, Oudijk MA, Bekker MN, Franssen MTM, et al. Nationwide implementation of a decision aid on vaginal birth after cesarean: a before and after cohort study. J Perinat Med 2021;49:783-90.

15. Paidas Teefey C, Reforma L, Koelper NC, Sammel MD, Srinivas SK, Levine LD, et al. Risk factors associated with cesarean delivery after induction of labor in women with class III obesity. Obstet Gynecol 2020;135:542-9.

16. Eberle A, Czuzoj-Shulman N, Azoulay L, Abenhaim HA. Induction of labor at 39 weeks and risk of cesarean delivery among obese women: a retrospective propensity score matched study. J Perinat Med 2021;49:791-6.

17. West HM, Jozwiak M, Dodd JM. Methods of term labor induction for women with a previous cesarean section. Cochrane Database Syst Rev 2017;6:CD009792.

18. Koenigbauer JT, Schalinski E, Jarchau U, Gauger U, Brandt K, Klaucke $S$, et al. Cervical ripening after cesarean section: a prospective dual center study comparing a mechanical osmotic dilator vs. Prostaglandin E2. J Perinat Med 2021;49:797-805.
19. Shah U, Bellows P, Drexler K, Hawley L, Davidson C, SangiHaghpeykar H, et al. Comparison of induction of labor methods for unfavorable cervices in trial of labor after cesarean delivery. J Matern Fetal Neonatal Med 2017;30:1010-5.

20. Miller TD, Davis G. Use of the Atad catheter for the induction of labour in women who have had a previous Caesarean section-a case series. Aust N Z J Obstet Gynaecol 2005;45:325-7.

21. Stark M. An evidence based caesarean section suggested for universal use. J Perinat Med 2021;49:806-8.

22. Kaps C, Schwickert A, Dimitrova D, Nonnenmacher A, Siedentopf J-P, Henrich W, et al. Online survey on uterotomy closure techniques in caesarean section. J Perinat Med 2021;49: 809-17.

23. Stark M. Optimised meta-analysis should be based on standardized methods. BJOG An Int J Obstet Gynaecol 2011;118: 765-6.

24. Hohlagschwandtner M, Ruecklinger E, Husslein P, Joura EA. Is the formation of a bladder flap at cesarean necessary? A randomized trial. Obstet Gynecol 2001;98:1089-92.

25. Stark M. Is bladder flap omission during Cesarean Section justified? Eur J Obstet Gynecol Reprod Biol 2020;249:108.

26. Rorie DK, Newton M. Histologic and chemical studies of the smooth muscle in the human cervix and uterus. Am J Obstet Gynecol 1967;99:466-9.

27. Stark M. Does size matter? J Turk Ger Gynecol Assoc 2016;17:175.

28. Pulvermacher C, Van de Vondel P, Gerzen L, Gembruch U, Welchowski T, Schmid M, et al. Analysis of cesarean section rates in two German hospitals applying the 10-Group Classification System. J Perinat Med 2021;49;818-29.

29. Robson M, Murphy M, Byrne F. Quality assurance: the 10-Group Classification System (Robson classification), induction of labor, and cesarean delivery. Int J Gynaecol Obstet 2015;131(1 Suppl): S23-7.

30. Odent $M$. Three kinds of cesarean sections: the fetal/neonatal perspective. J Perinat Med 2021;49:763-6. 